\title{
Amplitude Modulation of Relative Humidity by Wind in Northeast China: the Formation of Variance Annual Cycle in Relative Humidity
}

\section{Da Nian}

Peking University

\section{Yu Huang}

Peking University

\section{Zuntao Fu (D fuzt@pku.edu.cn )}

Peking Unniversity https://orcid.org/0000-0001-9256-8514

\section{Research Article}

Keywords: relative humidity, variance annual cycle, amplitude modulation, wind speed, East Asian monsoon

Posted Date: September 29th, 2021

DOI: https://doi.org/10.21203/rs.3.rs-774386/v1

License: (c) (i) This work is licensed under a Creative Commons Attribution 4.0 International License. Read Full License

Version of Record: A version of this preprint was published at Climate Dynamics on February 8th, 2022. See the published version at https://doi.org/10.1007/s00382-022-06175-7. 

. .

\section{Amplitude Modulation of Relative Humidity by Wind in Northeast}

\section{China: the Formation of Variance Annual Cycle in Relative Humidity}

Da Nian $^{1} \quad$ Yu Huang ${ }^{1} \quad$ Zuntao $\mathrm{Fu}^{1}$

1. Lab for Climate and Ocean-Atmosphere Studies, Dept. of Atmospheric and Oceanic Sciences, School of Physics, Peking University, Beijing, 100871, China . , (5)

Corresponding author: Zuntao Fu, Lab for Climate and Ocean-Atmosphere Studies,

Dept. of Atmospheric and Oceanic Sciences, School of Physics, Peking University, Beijing, 100871, China. Email: fuzt@ pku.edu.cn; Tel: 86-010-62767184

\section{Abstract}


Relative humidity has an important impact not only on climate change and ecosystems but also on human life. The intensity of high-frequency fluctuations in relative humidity over Northeast China shows a predominant seasonally dependent structure, which may be closely related to regional monsoon activities. However, the factors responsible for this phenomenon remain unknown. This study defines the Variance Annual Cycle (VAC) to describe this seasonally dependent intensity structure of high-frequency relative humidity fluctuations. Relative humidity VAC shows a high correlation with low-frequency oscillations of wind speed. We examine the instantaneous amplitude-phase correlation map and amplitude modulation (AM) index between relative humidity and wind speed. We find that the wind speed with a period around 140-420 days has a significant amplitude modulation effect on the relative humidity with a period around 2-90 days over most regions in Northeast China, which reveals that the low-frequency oscillations of wind speed amplitudemodulate on the high-frequency fluctuations of relative humidity. To explore the physical mechanism behind this modulation, we examine the monthly mean patterns of the atmospheric fields. The patterns indicate that this amplitude modulation is induced by the evolution and transition of East Asian winter monsoon and summer monsoon.

Key words: relative humidity $\cdot$ variance annual cycle $\cdot$ amplitude modulation $\cdot$ wind speed $\cdot$ East Asian monsoon 


\section{Introduction}

Relative humidity plays a crucial role in climate change, vegetation growth and human living and health (Byrne and O'Gorman, 2018; Sherwood and Fu, 2014; Sun et al., 2016). As a direct observation of atmospheric moisture content, relative humidity is an important atmospheric variable that can reflect the combined effect of temperature and moisture budget (Wang and Gaffen, 2001). For the monsoon system, in which the temperature and local water vapor budget change drastically during the beginning, development, and ending process, relative humidity is a physical quantity with great potential to describe its evolution process. Previous study shows that the variance of relative humidity fluctuations before the onset of the Indian summer monsoon is feasible to determine the optimal geographic location for predicting the monsoon, and the annual cycle of relative humidity can be beneficial for the prediction of monsoon onset and withdrawal (Stolbova et al., 2016). Previous studies have also found that the change of relative humidity in West Africa is controlled by the West African monsoon system, and it can be well predicted with the occurrence and disappearance of the monsoon (Broman et al., 2014). In addition, Pang et al. studied changes in relative humidity and its relationship with zonal wind speed and precipitation to explore the source of Indian summer monsoon precipitation (Pang et al., 2004). Obviously, studies on the changes of relative humidity in the monsoon region can help to better understand the physical processes in the monsoon activity and contribute greatly to the monsoon prediction. In light of the risk of extreme events increasing greatly in the monsoon regions with global warming (Zhang et al., 2018), the correct understanding of the physical process of relative humidity in monsoon regions is of great importance.

However, the study on relative humidity changes is still not sufficient, especially over China, which is greatly affected by the multiple monsoon systems (Ding, 1992; Ding and Wang, 2008; Wang and Gaffen, 2001; You et al., 2015). Most studies focus on the long-term trend of relative humidity (Shi et al., 2019; Song et al., 2012; Xie et al., 2011), and there is only a little concern about the characteristics of 
relative humidity variability. Limited studies have shown that Northeastern China's relative humidity anomalies have strong long-range memory and multi-fractal properties (Chen et al., 2007; Gao and Fu, 2013; Lin et al., 2007). This strong non-linearity indicates that there may be complex dynamical processes and nonlinear interactions in these regions, which may be a convoluted effect of the monsoon activities. Moreover, no clear consensus exists on the dynamics behind this. Directly observing the relative humidity anomaly in Northeast China, one will find that its own intensity exhibits a significant annual cycle change (shown in Figure 1a), but there is no study on the cause of this phenomenon. So what's the reason for the formation of this yearly periodic signal over Northeast China? What are the meteorological and dynamical mechanisms behind this situation, and is it related to local monsoon activities?

The high-frequency fluctuations in relative humidity anomaly have annual intensity changes that may be related to low-frequency wind speed changes, which is a reasonable conjecture. Since large-scale atmospheric circulation activities are often accompanied by changes in surface moisture flux and temperature, which have a great influence on relative humidity (De et al., 2016; Krishnamurti et al., 1991). As the previous study on the Indian summer monsoon shows, relative humidity is sensitive to the change of the related circulation (Stolbova et al., 2016). Wind speed can simply describe the changes in atmospheric circulation (Xu et al., 2006). And previous study has also shown that there is a highly nonlinear relationship between wind fields and relative humidity (Krishnamurti et al., 1991). Wind speed can dominate the change of regional evapotranspiration (Liu and Zhang, 2013), thereby affecting the water vapor budget and relative humidity. Therefore, this study will start from the relationship between relative humidity anomaly and wind speed to explore the possible physical mechanisms to the annual cycle change in relative humidity anomaly intensity.

In this study, we will first define the annual cycle of the relative humidity anomaly intensity, and study its correlation with the annual change of wind speed. Then we determine the frequency band that is the leading component in the 
cross-scale interaction between relative humidity and wind speed. Next, the amplitude modulation relationship can be identified and quantified between high frequency fluctuations in the relative humidity and low frequency oscillations in wind speed. At last we examine the monthly mean patterns of atmospheric fields to analyze the mechanism behind the amplitude modulation.

The organization of this article is as follows: Section 2 describes the data and methodology used in this study. Section 3 shows the results. Section 4 discusses the implications from these results and concludes the study.

\section{Data and methods}

\subsection{Data}

In this study, daily observations of relative humidity and wind speed data are used. These records are obtained from the China Meteorological Administration (http://data.cma.cn/) for the period from 1970.1.1 to 2018.12.30. The quality of the data has been controlled by removing stations with missing data for 31 or more days during the whole period. Linear interpolation has been used to fill the missing data less than 31 days. Then 132 stations from Northeast China (within $112^{\circ} \mathrm{E}$ to $135^{\circ} \mathrm{E}$, $39^{\circ} \mathrm{N}$ to $54^{\circ} \mathrm{N}$ ) are retained while ensuring that that each station had records of relative humidity and wind speed.

In addition to analysis the atmospheric fields, we also use the data of daily mean sea level pressure over 1979 to 2018 with resolution $2.5^{\circ} * 2.5^{\circ}$ from NCEP/DOE 2 Reanalysis data provided by the NOAA/OAR/ESRL PSL, Boulder, Colorado, USA (at https://www.psl.noaa.gov/data/gridded/data.ncep.reanalysis2.surface.html). And the daily $10 \mathrm{~m}$ u-wind and $10 \mathrm{~m}$ v-wind component over 1979 to 2018 with Gaussian grid from NCEP/DOE 2 Reanalysis data (at https://www.psl.noaa.gov/data/gridded/data.ncep.reanalysis2.gaussian.html) are also used. The Climatological Annual Cycle (CAC) of relative humidity and wind speed takes the long-term average value of each day in a calendar year from 1970 to 2018, filtering out high-frequency fluctuations below 14 days. And the relative humidity 
anomalies are obtained by removing the CAC from the raw measurements, which is similar to previous studies (Huybers et al., 2014).

\subsection{Definition of Variance Annual Cycle (VAC) of relative humidity}

Relative humidity anomaly displays a predominant seasonally dependent change in its intensity, which can be directly observed in a typical meteorological station in Northeast China (Fig. 1a). This nearly periodic change seems to take a yearly cycle. Variance of each calendar day can effectively describe these changes in intensity in a simple way. For a concise and effective description of this yearly periodic intensity in relative humidity anomaly, we define a Variance Annual Cycle (VAC), which is similar to the definition of the relative humidity CAC. VAC is the standard deviation of each calendar day $i$ in a year $(i=1,2 \ldots 365)$ over $N$ years:

$$
V A C_{i}=\sqrt{\frac{1}{N} \sum_{j=1}^{N}\left(x_{i, j}-\mu_{i}\right)^{2}}
$$

where $x_{i, j}$ is the raw value of day $i$ in year $j$, and $\mu$ is the mean value of day $i$ over $N$ years.

\subsection{Instantaneous amplitude-phase correlation map}

It should be pointed out that VAC is only a mean description of seasonally dependent change in the intensity of relative humidity anomaly, in order to determine the dominant frequency of the interaction between relative humidity and wind speed, the method from Palušs study on the annual-scale temperature amplitude being modulated by the 7-8 year oscillation is adopted (Paluš, 2014) to explore the instantaneous variations in the intensity of relative humidity anomaly and wind speed. Since the long-term temperature record contains complicated variations on multiple time scales, which correspond to the oscillation and synchronization observed on various scales of atmospheric dynamics. Paluš used wavelet filters and Hilbert transform methods to quantify the dependence between the instantaneous amplitude and frequency of the oscillation dynamics obtained in the time series (Paluš, 2014). The relative humidity is affected by the balance of moisture budget and temperature, 
which has a multiple-timescale variation. Here, the effect of wind on relative humidity seems to be cross-scaled, which is similar to the case found by Paluš (Paluš, 2014).

We adopt the continuous complex wavelet (CCWT) method to decompose the relative humidity time series as components of different periods, then use the Hilbert transform to obtain the instantaneous amplitude and instantaneous phase for each component. For arbitrary real-valued time series $x(t)$, CCWT can obtain its complex wavelet analytic signal $s(t)$ at a certain frequency, choosing a non-orthogonal Morlet wavelet base, which can be written as:

$$
s(t)=\mathrm{s}_{\mathrm{R}}(\mathrm{t})+\mathrm{is}_{\mathrm{I}}(\mathrm{t})=A(t) e^{i \phi(t)},
$$

where $s_{\mathrm{R}}(\mathrm{t})$ is the real part of and $s_{I}(t)$ can be obtained by Hilbert transform. And $A(t)$ is the instantaneous amplitude and $\phi(t)$ is the instantaneous phase. Then instantaneous amplitude can be obtained:

$$
A(t)=\sqrt{\mathrm{s}_{\mathrm{R}}(\mathrm{t})^{2}+\mathrm{s}_{\mathrm{I}}(\mathrm{t})^{2}}
$$

And the instantaneous phase is

$$
\phi(t)=\arctan \frac{\mathrm{s}_{\mathrm{I}}(\mathrm{t})}{\mathrm{s}_{\mathrm{R}}(\mathrm{t})} \text {. }
$$

In this study, the instantaneous phase of wind speed $\phi_{\text {wind }}(t)$ and the instantaneous amplitude of relative humidity $A_{R H}(t)$ are calculated for each station over the studied region. In order to avoid the marginal effects of the wavelet method, the first and last 2000 data points have been excluded. Then we calculate the Pearson correlation between $\phi_{\text {wind }}(t)$ and $A_{R H}(t)$ for different frequency. Here the significance test is carried out by using 1000 pairs of phase random surrogates generated for relative humidity and wind speed, in which surrogates can effectively destroy the information in the phase. Each pair of surrogates repeats the same processing as the original relative humidity and wind speed data, obtaining the $\phi(t)$ in the wind speed surrogates and $A(t)$ in the relative humidity surrogates, and calculating the Pearson correlation between them. The result is significant if the Pearson correlation between $\phi_{\text {wind }}(t)$ and $A_{R H}(t)$ is greater than the the 95th percentile of the result from surrogates. 


\subsection{Amplitude Modulation index}

In order to quantify the modulation intensity of wind speed at each station to relative humidity, we adopt a statistical technique which is popular in quantifying amplitude modulation in wall turbulence problem (Mathis et al., 2009), calculating the Amplitude Modulation index. We first use CCWT filter to extract low-frequency oscillation of wind speed variability $u_{\text {wind }-L}$ (the black line in Figure $3 \mathrm{~b}$ ), and combine CCWT with Hilbert transform to extract the instantaneous amplitude $\left(A_{R H-H}\right)$ of high-frequency relative humidity fluctuations. The series $A_{R H-H}(t)$ also represents the intensity or the envelope of the relative humidity anomaly (Figure 1a).

To remove the small-scale interference of the carrier signal obtained by the Hilbert transform (Mathis et al., 2009), we filter out the small-scale (smaller than 90 days) oscillations in the instantaneous amplitude and get filtered envelope $A_{R H-H}{ }^{\prime}$ (the red line shown in Figure 3b). Then, the Amplitude Modulation (AM) index, a meaningful correlation coefficient between the amplitude of small-scale fluctuations in relative humidity and the large-scale variability of wind speed, can be calculated as a quantification of the AM degree (Mathis et al., 2009):

$$
\mathrm{AM}=\frac{\overline{\overline{u_{\text {wlnd }-L^{\prime}} A_{R H-H^{\prime}}}}}{\sqrt{\overline{u_{\text {wlnd }-L}^{2}}} \sqrt{A_{R H-H}^{\prime 2}}}
$$

where $\sqrt{\overline{u_{\text {wind }-L}^{2}}}$ denotes the root mean square of $u_{\text {wind }-L}$.

For the significance test, it is also determined by generating 1000 pairs of phase randomized surrogates for the wind speed and relative humidity and repeating the similar procedure above to calculate the AM index from surrogates. The AM index of wind speed and relative humidity is significant if it is greater than the 95th percentile of AM indexes from surrogates. This procedure is similar to the choice from Mathis and can effectively detect and quantify the amplitude modulation strength. The amplitude of high-frequency relative humidity fluctuation $A_{R H-H}{ }^{\prime}$ shows high coherence with the low-frequency variability of wind $u_{\text {wind }-L}$ at the typical station $50136\left(122.31^{\circ} \mathrm{E}, 52.58^{\circ} \mathrm{N}\right.$, Figure $\left.3 \mathrm{~b}\right)$, which implies the high extent of amplitude modulation between them. 


\section{Results}

\subsection{High correlation between VAC of relative humidity and CAC of Wind Speed}

Relative humidity VAC shows the deviation of raw data from climatology each day in a calendar year (Figure 1b), which corresponds to the multi-year average of the intensity changes of relative humidity anomalies in a year. There is a marked bimodal structure within one year, which shows low values in winter and summer, and high values in spring and autumn. This structure is completely inversed to the CAC structure (Figure 1c). The relative humidity VAC also represents the amplitude of high-frequency fluctuations averaged over many years (Figure 1a). The inverted structure of VAC relative to CAC indicates that the annual change of relative humidity does not modulate its own high-frequency fluctuations.

To explore the causes of VAC in relative humidity anomaly, we firstly consider the hint from the definition of relative humidity. Relative humidity is the ratio of vapor pressure e and saturation vapor pressure $e_{s}$ :

$$
\text { relative humidity }=\frac{\mathrm{e}}{\mathrm{e}_{\mathrm{s}}} \text {. }
$$

The vapor pressure is the partial pressure of water vapor in the atmosphere, which is closely linked with moisture budget. The saturation vapor pressure is controlled by air temperature and positively correlated with it. Then the process of monsoon will play an important role on the change of relative humidity, because the local moisture budget and temperature will change greatly during the onset and ending of the monsoon. The local wind speed can simply and roughly describe the changes in the monsoon (Xu et al., 2006). Therefore, the wind speed may affect the change of the relative humidity VAC.

In order to explore the reason for the VAC in relative humidity anomaly, we compare the VAC of relative humidity with the CAC of wind speed. The observation in a typical station $50136\left(122.31^{\circ} \mathrm{E}, 52.58^{\circ} \mathrm{N}\right)$ shows an analogous structure between relative humidity's VAC and wind speed's CAC, and the changes of the two are almost 
in phase (Figure 2a). This implies that there is a strong correlation between wind speed and relative humidity. To check if there is a consistent high correlation between the two over the whole given region, we calculate the Pearson correlation between relative humidity's VAC and wind speed's CAC for all meteorological stations' records in Northeast China. The significance level is determined by Monte Carlo testing by generating 1000 pairs of phase randomized surrogates for relative humidity and wind speed. The phase random randomized surrogates (Schreiber and Schmitz, 1996) can keep the power spectrum density of the original data but with a random phase, excluding the in-phase relationship from nonlinear interaction between them. Then we calculate the correlation between VAC in relative humidity surrogates and $\mathrm{CAC}$ in wind speed surrogates. If the result is greater than the 95th percentile of the correlation results of the surrogates, it is a significant in-phase correlation between relative humidity VAC and wind speed CAC. The result shows that most meteorological stations present a significant correlation between relative humidity's VAC and wind speed's CAC, which indicates a cross-scale nonlinear interaction between high-frequency fluctuations in relative humidity and the low-frequency oscillations in wind speed.

\subsection{The cross-scale interaction of relative humidity from wind speed}

To detect the interaction between relative humidity and wind speed and figure out the key frequency band of the interaction, we explored the cross-frequency phase-amplitude coupling relationship between wind speed and relative humidity by calculating the instantaneous amplitude-phase correlation map. Taking the station $50136\left(122.31^{\circ} \mathrm{E}, 52.58^{\circ} \mathrm{N}\right)$ as an example, Figure 3a shows that there exist significant cross correlations between wind speed with a period of 140-420 days and relative humidity with a period of 2-90 days. Analyzing all 132 stations in this studied region, the results show that this phenomenon not only occurs in a typical station but also in most stations in Northeast China (not shown). This means that the low-frequency oscillation of wind speed corresponding to 140-420 days does modulate the 
high-frequency fluctuations of relative humidity corresponding 2-90 days. Previous studies suggest that cross-scale interactions are the intrinsic property within the climate systems due to the nonlinear dynamics nature, and similar cross-scale modulation phenomena have been found in the air temperature, El Niño-Southern Oscillation and Madden-Julian Oscillation (Stein et al., 2011; Paluš, 2014; Jajcay et al., 2018; Martin et al., 2021). Here the newly discovered wind-humidity relationship can contribute to the better understanding of relevant studies.

\subsection{The amplitude modulation of wind speed on relative humidity}

In order to infer the modulation intensity of wind speed at each station to relative humidity, the AM index is computed between relative humidity with a period of 2-90 days and wind speed with a period of 140-420 days. After computing AM index over all stations in Northeast China, the result shows that most stations have significant AM indices between wind speed and relative humidity (Figure 4). This result indicates that the amplitude modulation of wind speed on relative humidity is significant in most stations of Northeast China. The distribution of AM index has a high consistency with the correlation between relative humidity VAC and wind speed CAC (Figure 4 and Figure 2b). This suggests that the amplitude modulation corresponds well to the previous results and explains the correlation between the two variables. In the next section, we aim to understand mechanism behind this amplitude modulation phenomenon.

\subsection{The implication of winter and summer monsoon for VAC of relative humidity}

To understand the implication of wind on relative humidity, we analyze the monthly mean patterns of the atmospheric fields. Checking the relevant large-scale atmospheric conditions on each month can help understand how wind affects relative humidity. The monthly mean patterns averaged over 40 years (1979-2018) of 10m u-wind, 10m v-wind, and sea level pressure data from NCEP reanalysis are calculated. It should be noted that the reanalysis wind data is given at $10 \mathrm{~m}$, which is different 
from the surface observation (measured on $10 \mathrm{~m}$ ). However, the reanalysis data is only applied to provide the large-scale atmospheric circulation background of the wind field, so the impact of the height difference can be ignored.

As a result, wind and sea level pressure exhibit distinct seasonal cycles, among which monsoon characteristics are recognizable (Figure 5). In January, the monthly mean pattern shows the typical features of the East Asian winter monsoon. The northwest wind enters Northeast China from Mongolia and leaves east and south, which carries cold and dry air from high-latitude continents into Northeast China (Jhun and Lee, 2004). The influence of low temperature dominates, resulting in high relative humidity in winter. When it comes to April and May, the northwest wind and westerly wind began to change into the south wind, generating cyclones in northeastern China. In June and July, the monthly mean of sea level pressure shows a low-pressure center over Northeast China, warm winds coming from the south low-latitude ocean carry sufficient water vapor, which is the typical characteristic of the East Asian summer monsoon (Ding, 1992). High water vapor content accounts for the main role in the high relative humidity in summer. Then in September and October, there is a transition from the summer monsoon to the winter monsoon. In December, the pattern of the winter monsoon reappeared.

The evolution and transition of monsoons above reveal the physical mechanisms behind the amplitude modulation of wind speeds to relative humidity. Figure $2 \mathrm{a}$ exhibits the low relative humidity VAC values under the two in-monsoon states, corresponding to the winter monsoon periods in December, January, and February, and the summer monsoon periods in June, July, and August. During in-monsoon periods, the mean wind direction remains nearly the same (Figure 5), implying the consistent atmospheric activity and weather processes. There are relatively similar temperature and atmospheric humidity states during the summer monsoon period, resulting in a small change in relative humidity in summer (Figure 1b), coinciding with low amplitude and low value in VAC for relative humidity in the summertime (Figure 1a and 1c). The situation in the winter monsoon period shows a similar 
condition, which also corresponds to a low value in relative humidity VAC. Although the values of relative humidity CAC in summer and winter are both high, the physical mechanisms behind them are completely different. Therefore, from a relatively warm and humid state to a relatively cold and dry state, the transition period from summer monsoon to winter monsoon experiences dramatic changes in temperature and atmospheric humidity, which will lead to large fluctuations in relative humidity. Accordingly, relative humidity VAC reaches the peak value during the transition from summer monsoon to winter monsoon in September and October. And so does the periods of transition from winter monsoon to summer monsoon in April and May (Figure 2a).

The spatial distribution of AM index can reflect the impact from topography during the monsoon activity over Northeast China. Many of the high values of the AM index are located on the west (windward) side of the mountain, nevertheless the values on the east (leeward) side of the mountains are lower (Figure 4). The west sides of mountains are windward slopes for the west and northwest winds during the winter monsoon in northeastern China (Figure 5). Weather changes in these areas are more affected by wind. The southeast region shows that the southern side of the mountain also has a larger AM value, which corresponds to the windward slope formed by the main southerly wind in summer. Here, the distribution of AM index actually characterizes the combined influences of the monsoons and topography. This common combined influence of the monsoons and topography also appears in the local precipitation. As a topographical barrier, the Andes Mountains determine the precipitation pattern in South America to a large extent (Boers et al., 2014; Gelbrecht et al., 2018). The windward slopes (east) of the Andes have abundant rainfall and are closely related to extreme precipitation (Boers et al., 2013; Boers et al., 2015), while the leeward slopes (west) are relatively dry (Wolf et al., 2020).

\section{Discussion and conclusion}

The observation shows that relative humidity over Northeast China shows a 
dominant seasonally dependent change in its intensity. In this study, we defined the climatological variance annual cycle VAC to describe this seasonally dependent change of relative humidity intensity. The relative humidity VAC has a bimodal structure. This structure is out of phase to the relative humidity CAC, which shows that VAC is not produced by its own CAC modulation. To explore the formation of relative humidity VAC, we compare the CAC of wind speed measured at the same meteorological station with the VAC of relative humidity. A significant high correlation between relative humidity VAC and wind speed CAC is demonstrated over most stations in Northeast China. This implies that there is an interaction between low-frequency wind speed oscillations and high-frequency relative humidity fluctuations. Then we combine the wavelet method and Hilbert transform to calculate the correlation map between the instantaneous amplitude of relative humidity and the instantaneous phase of wind speed at each frequency. The correlation map displays a significantly correlated frequency band, corresponding to wind speeds of approximately 140-420 days and relative humidity of approximately 2-90 days. This indicates that the low-frequency oscillations of the wind speed modulate the high-frequency fluctuations of the relative humidity. Using AM index to quantify the intensity of amplitude modulation between them, and the result suggests that most stations over Northeast China have significant AM index. To examine the physical mechanisms behind this amplitude modulation, we analyze the monthly mean circulation patterns, which reveal that the amplitude modulation is induced by the evolution and transition of East Asian winter monsoon and summer monsoon. The relative humidity remains relatively stable during the monsoon period and the value is low in relative humidity VAC in winter and summer. Due to the transition from one state to another, the relative humidity within the two monsoon transition periods undergoes great changes, resulting in high values in relative humidity VAC.

Actually the cross-scale interaction in the system always accompanies by nonlinear features (Mathis et al., 2009). The above presented results show that the high-frequency fluctuations of relative humidity are amplitude-modulated by the 
low-frequency wind speed oscillations. Therefore, the relative humidity anomaly as a carrier signal is multiple-timescale variability with different fluctuations and may possess nonlinear behaviors. It should be inferred that relative humidity fluctuations with a strong $\mathrm{AM}$ index has strong nonlinear characteristics. In order to explore the nonlinear features in relative humidity, we quantify the multi-fractal strength of relative humidity anomalies over Northeast China, which is a nonlinear characteristic, by means of the ESS-MF-DFA method (Nian and Fu, 2019). The result shows a great consistency (spatial correlation coefficient over the whole region is 0.54 , significant at 99\% level for Student's $t$ test) between the multi-fractal intensity and AM index. The windward slope and valley regions with high AM index also present strong multi-fractal characteristics. This confirms that the nonlinear features of relative humidity are at least partially related to the wind speed amplitude-modulation to the high frequency relative humidity fluctuations.

This study focuses on the amplitude modulation from the low-frequency oscillations of wind speed to the high-frequency fluctuations of relative humidity in the Northeast region, which is also the reason for the formation of relative humidity VAC. The relative humidity VAC phenomenon does not only occur in Northeast China. The occurrence mechanism of relative humidity VAC phenomenon over different regions may be different, for example, regional evaporation and temperature may be infected by vegetation (Durre and Wallace, 2001), which is temporarily out of the scope of this study. Northeast China is a region with multiple-monsoon regulation. The study of relative humidity VAC is helpful to understand the monsoon activity and its impacts, and it is also helpful to explore new methods of monsoon forecasting (Stolbova et al., 2016) and effective seasonal prediction combined machine learning (Mitsui and Beors, 2021). In addition to relative humidity, VAC will also appear in other variables (Rybski et al., 2008). More research is needed in the future to explore the feasibility of VAC phenomenon and corresponding mechanisms found in this study. 
442 The authors thank John M. Wallace for his constructive suggestions. The authors

443 acknowledge the supports from National Natural Science Foundation of China (Nos.

$444 \quad 41675049$ and 41975059).

445

446

Declarations

447

Conflict of interest The authors declare no competing interests.

\section{Data availability}

The data that support the findings of this study are openly available at the following URL/DOI:

http://data.cma.cn/

The NCEP-NCAR reanalysis daily data used in this study can be obtained from the following

https://www.psl.noaa.gov/data/gridded/data.ncep.reanalysis2.gaussian.html

\section{ORCID iDs}

Da Nian · https://orcid.org/0000-0002-2320-5223

Yu Huang · https://orcid.org/0000-0002-7930-9056

Zuntao Fu · https://orcid.org/0000-0001-9256-8514

\section{Reference:}

Boers N, Bookhagen B, Marwan N, Kurths J, Marengo J (2013) Complex networks identify spatial patterns of extreme rainfall events of the South American Monsoon System. Geophysical Research Letters 40(16): 4386-4392.

Boers N, Rheinwalt A, Bookhagen B, Barbosa HM, Marwan N, Marengo J, Kurths J (2014) The South American rainfall dipole: A complex network analysis of extreme events. Geophysical Research Letters 41(20): 7397-7405

Boers N, Bookhagen B, Marengo J, Marwan N, von Storch JS, Kurths J (2015) Extreme rainfall of the South American monsoon system: a dataset comparison using complex networks. Journal of Climate 28(3): 1031-1056

Broman D, Rajagopalan B, Hopson T (2014) Spatiotemporal variability and predictability of 
relative humidity over West African monsoon region. Journal of Climate 27(14): 5346-5363

Byrne MP and O'Gorman PA (2018) Trends in continental temperature and humidity directly linked to ocean warming. Proceedings of the National Academy of Sciences 115(19): 4863-4868

Chen X, Lin GX, Fu ZT (2007) Long-range correlations in daily relative humidity fluctuations: a new index to characterize the climate regions over China. Geophysical Research Letters 34(7): 801-804

De S, Hazra A, Chaudhari HS (2016) Does the modification in "critical relative humidity" of NCEP CFSv2 dictate Indian mean summer monsoon forecast? Evaluation through thermodynamical and dynamical aspects. Climate Dynamics 46(3-4): 1197-1222

Ding YH (1992) Summer monsoon rainfalls in China. Journal of the Meteorological Society of Japan Ser. II 70(1B): 373-396

Ding YH and Wang ZY (2008) A study of rainy seasons in China. Meteorology and Atmospheric Physics 100(1-4): 121-138

Durre I and Wallace JM (2001) The warm season dip in diurnal temperature range over the eastern United States. Journal of Climate 14(3): 354-360

Gao LH and Fu ZT (2013) Multi-fractal behaviors of relative humidity over China. Atmospheric and Oceanic Science Letters 6(2): 74-78

Gelbrecht M, Boers N, Kurths J (2018) Phase coherence between precipitation in South America and Rossby waves. Science advances 4(12): eaau3191

Huybers P, McKinnon KA, Rhines A, Tingley M (2014) US daily temperatures: The meaning of extremes in the context of nonnormality. Journal of Climate 27(19): 7368-7384

Jajcay N, Kravtsov S, Sugihara G, Tsonis AA, Paluš M (2018) Synchronization and causality across time scales in El Niño Southern Oscillation. npj Climate and Atmospheric Science 1: 33

Jhun JG and Lee EJ (2004) A new East Asian winter monsoon index and associated characteristics of the winter monsoon. Journal of Climate 17(4): 711-726

Krishnamurti T, Xue J, Bedi H, Ingles K, Oosterhof D (1991) Physical initialization for numerical weather prediction over the tropics. Tellus B 43(4): 53-81

Lin GX, Chen X, Fu ZT (2007) Temporal-spatial diversities of long-range correlation for relative humidity over China. Physica A 383(2): 585-594

Liu X and Zhang D (2013) Trend analysis of reference evapotranspiration in Northwest China: the roles of changing wind speed and surface air temperature. Hydrological Processes 27(26): 3941-3948

Martin Z, Son SW, Butler A, Hendon H, Kim H, Sobel A, Yoden S, Zhang C (2021) The influence of the quasi-biennial oscillation on the Madden-Julian oscillation. Nature Review Earth \& Environment 2: 477-489.

Mathis R, Hutchins N, Marusic I (2009) Large-scale amplitude modulation of the small-scale structures in turbulent boundary layers. Journal of Fluid Mechanics 628: 311-337

Mitsui T and Beors N (2021) Seasonal prediction of Indian summer monsoon onset with echo state networks. Environ. Res. Lett. 16: 074024

Nian D and Fu ZT (2019) Extended self-similarity based multi-fractal detrended fluctuation analysis: a novel multi-fractal quantifying method. Communications in Nonlinear Science and Numerical Simulation 67: 568-576 
Paluš M (2014) Multiscale atmospheric dynamics: cross-frequency phase-amplitude coupling in the air temperature. Physical Review Letters 112(7): 078702

Pang H, He Y, Zhang Z, Lu A, Gu J (2004) The origin of summer monsoon rainfall at New Delhi by deuterium excess. Hydrology and Earth System Sciences 8(1): 115-118

Rybski D, Bunde A, Von Storch H (2008) Long-term memory in 1000-year simulated temperature records. Journal of Geophysical Research-Atmospheres 113(D2): D02106

Schreiber T, Schmitz A (1996) Improved surrogate data for nonlinearity tests. Physical Review Letters 77(4): 635

Sherwood S and Fu Q (2014) Climate change. A drier future? Science 343(6172): 737-739

Shi F Z, Zhao C Y, Zhou X, Li X H (2019) Spatial variations of climate-driven trends of water vapor pressure and relative humidity in Northwest China. Asia-Pacific Journal of Atmospheric Sciences 55(2): 221-231

Song YF, Liu YY, Ding YH (2012) A study of surface humidity changes in China during the recent 50 years. Acta Meteorologica Sinica 26(5): 541-553

Stein K, Timmermann A, Schneider N (2011) Phase Synchronization of the El Niño-Southern Oscillation with the Annual Cycle. Physical Review Letters 107: 128501

Stolbova V, Surovyatkina E, Bookhagen B, Kurths J (2016) Tipping elements of the Indian monsoon: Prediction of onset and withdrawal. Geophysical Research Letters 43(8): 3982-3990

Sun B, Liu Y, Lei Y (2016) Growing season relative humidity variations and possible impacts on Hulunbuir grassland. Science Bulletin 61(9): 728-736

Wang JXL and Gaffen DJ (2001) Late-twentieth-century climatology and trends of surface humidity and temperature in China. Journal of Climate 14(13): 2833-2845

Wolf F, Bauer J, Boers N, Donner RV (2020) Event synchrony measures for functional climate network analysis: A case study on South American rainfall dynamics. Chaos 30(3): 033102

Xie BG, Zhang QH, Ying Y (2011) Trends in precipitable water and relative humidity in China: 1979-2005. Journal of Applied Meteorology and Climatology 50(10): 1985-1994

Xu M, Chang P, Fu C, Qi Y, Robock A, Robinson D, Zhang HM (2006) Steady decline of East Asian monsoon winds, 1969-2000: Evidence from direct ground measurements of wind speed. Journal of Geophysical Research-Atmospheres 111(D24): D24111

You Q, Min J, Lin H, Pepin N, Sillanpää M, Kang S (2015) Observed climatology and trend in relative humidity in the central and eastern Tibetan Plateau. Journal of Geophysical Research-Atmospheres 120(9): 3610-3621

Zhang WX, Zhou TJ, Zou LW, Zhang LX, Chen XL (2018) Reduced exposure to extreme precipitation from $0.5 \mathrm{C}$ less warming in global land monsoon regions. Nature Communications $9(1): 1-8$ 


\section{Figure captions}

Figure 1. Definition of RH Variance Annual Cycle (VAC). (a) Daily data of relative humidity (RH) anomaly for station 50136 in Northeast China from 1997 to 2004 (black line). The red line shows the envelope of the RH anomaly, and is also the instantaneous amplitude of RH fluctuation with a period of less than 90 days, extracted by wavelet analysis and Hilbert transform. (b) The RH climatology annual cycle (red line) and RH raw data from 1970 to 2018 (black dots). The red shading shows the standard deviation over 49 years for each day in a calendar year. (c) The RH climatology annual cycle "zoomed" in its individual scales. (d) The standard deviation over 40 years for each day in a calendar year change with time.

Figure 2. The high correlation between relative humidity (RH) Variance annual cycle (VAC) and wind speed climatology annual cycle (CAC). (a) the RH VAC and wind speed CAC for station 50136 in a calendar year. (b) The Pearson correlation between RH VAC and wind speed CAC for 132 stations over Northeast China. The black circle indicates stations with a significant correlation at $95 \%$ confidence based on a Monte Carlo test by generating 1000 surrogates using Phase Randomized Surrogate procedure. Most stations over Northeast China show significant correlations between RH VAC and wind speed CAC. VAC represents the amplitude of high-frequency fluctuation in RH anomaly, and CAC represents the annual cycle of wind speed. This also indicates there is a cross-scale modulation between RH and wind speed over Northeast China.

Figure 3. (a) The correlation map between wind speed phase and relative humidity (RH) amplitude at station 50136 in Northeast China. The value of the colored area represents the range with the significant Pearson correlation between the instantaneous phases of wind speed and the instantaneous amplitude of RH for the corresponding frequency bands. The significance level for the correlation map, obtained by 1000 phase-random surrogates, is coded in color if they are greater than $95 \%$ of surrogates' results. The significant correlation band of period 140 420 days for wind speed phase and period 2 90 days for RH amplitude indicates the cross-scale modulation of the phase of low-frequency oscillation in the daily wind speed on the amplitude of high-frequency fluctuations in the daily RH. (b) Wind speed low-frequency oscillation with a period of 140 420 days (CCWT as a filter) and RH high-frequency fluctuation amplitude with a period of 2 90 days (the instantaneous amplitude extracted by CCWT and filters out fluctuations 
less than 90 days). The result is calculated from daily data of station 50136.

584 Figure 4. The distribution of Amplitude Modulation (AM) index over Northeast China. The points with black circles outside represent the station with significant amplitude modulation between wind speed and RH. The AM index is significant when it is greater than the $95 \%$ results of 1000 phase randomized surrogates after the same procedure. The background color shows the elevation of the area. Most stations with significant AM indexes indicate the strong amplitude modulation effect of wind speed on RH over this area.

Figure 5. Monthly averages of wind speed $(\mathrm{m} / \mathrm{s})$ and sea level pressure $(\mathrm{Pa})$ in a year. The black vector in the figure represents the wind speed intensity and direction, and the background color shading represents the sea level pressure $(\mathrm{Pa})$. Both data are from the reanalysis dataset. The pink dash rectangle represents Northeast China, which is from $112^{\circ} \mathrm{E}$ to $135^{\circ} \mathrm{E}, 39^{\circ} \mathrm{N}$ to $54^{\circ} \mathrm{N}$. The monthly mean of the wind and sea level pressure exhibits the evolution of monsoons in a year over Northeast China. The monthly mean map in January and February shows the features of the Winter East Asian monsoon with mainly northwestern and western wind. Then the Winter East Asian monsoon decays and transits to Summer East Asian monsoon with the transition time in Apr and May. The map in June, July, and August shows the Summer East Asian monsoon with the mainly south wind. And the map in September and October show the transition from summer Figure 6. The distribution of multi-fractal strength of $\mathrm{RH}$ anomalies over Northeast China calculated by the ESS-MF-DFA method. The multi-fractal strength is significant when the value above 0.05. Most stations of this area show strong multi-fractal features, representing strong 605 

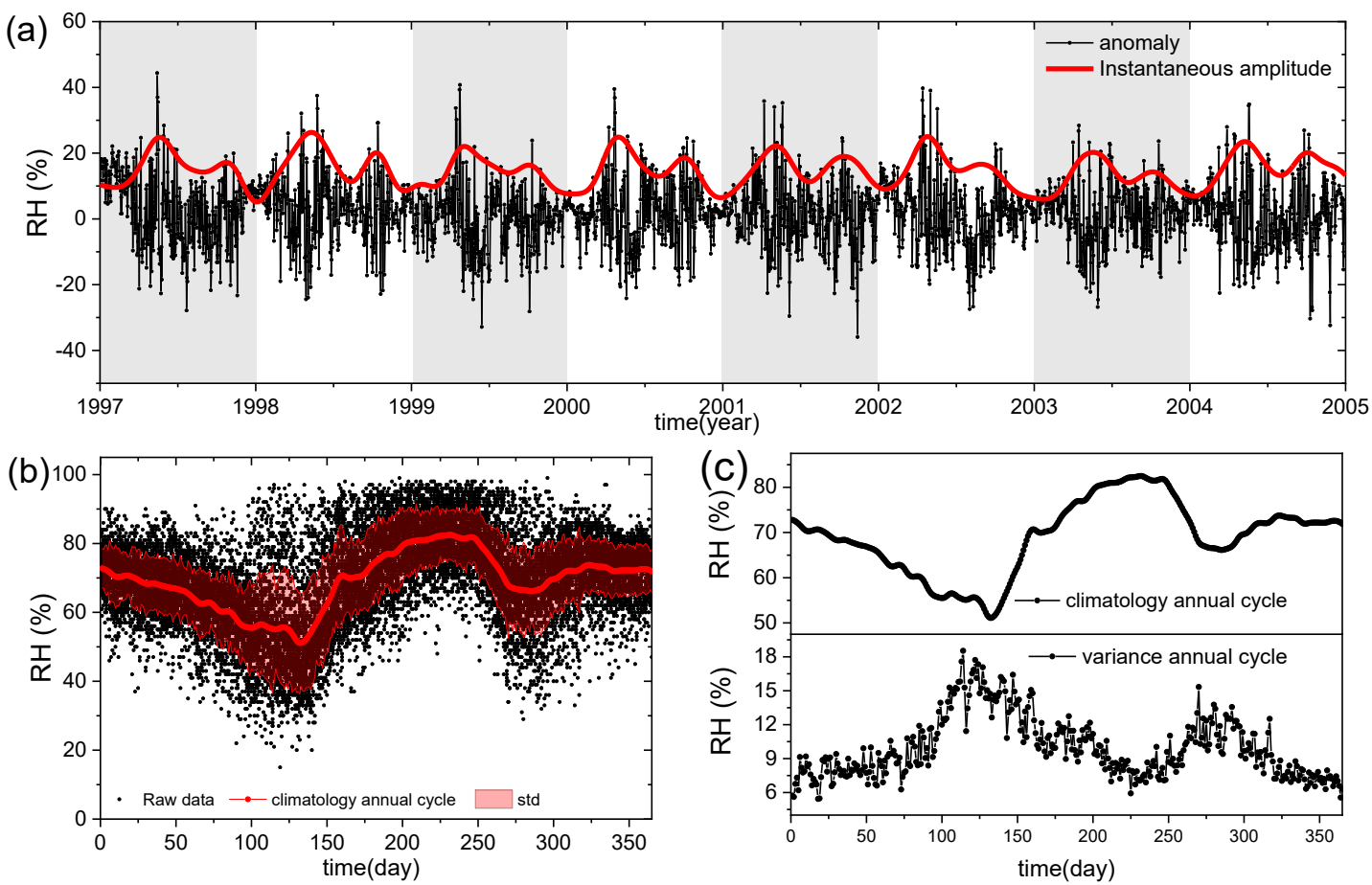

Figure 1. Definition of RH Variance Annual Cycle (VAC). (a) Daily data of relative humidity (RH) anomaly for station 50136 in Northeast China from 1997 to 2004 (black line). The red line shows the envelope of the RH anomaly, and is also the instantaneous amplitude of RH fluctuation with a period of less than 90 days, extracted by wavelet analysis and Hilbert transform. (b) The RH climatology annual cycle (red line) and RH raw data from 1970 to 2018 (black dots). The red shading shows the standard deviation over 49 years for each day in a calendar year. (c) The RH climatology annual cycle "zoomed" in its individual scales. (d) The standard deviation over 40 years for each day in a calendar year change with time. 

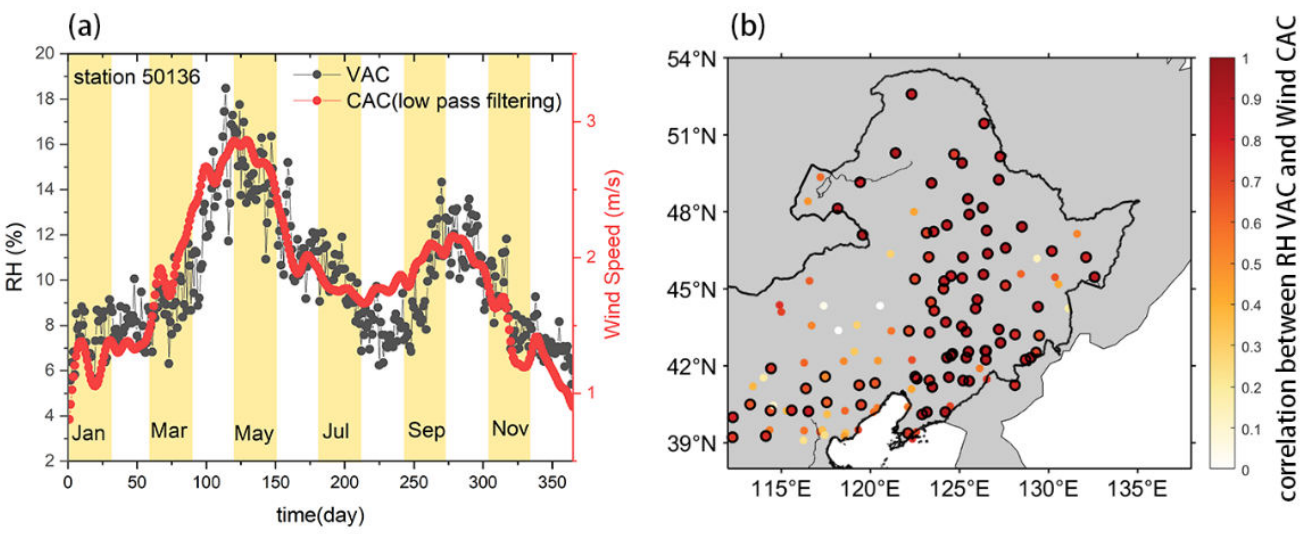

625 Figure 2. The high correlation between relative humidity (RH) Variance annual cycle (VAC) and wind speed climatology annual cycle (CAC). (a) the RH VAC and wind speed CAC for station 50136 in a calendar year. (b) The Pearson correlation between RH VAC and wind speed CAC for 132 stations over Northeast China. The black circle indicates stations with a significant correlation at $95 \%$ confidence based on a Monte Carlo test by generating 1000 surrogates using Phase Randomized Surrogate procedure. Most stations over Northeast China show significant correlations between RH VAC and wind speed CAC. VAC represents the amplitude of high-frequency fluctuation in RH anomaly, and CAC represents the annual cycle of wind speed.

633 This also indicates there is a cross-scale modulation between RH and wind speed over Northeast 634 China. 

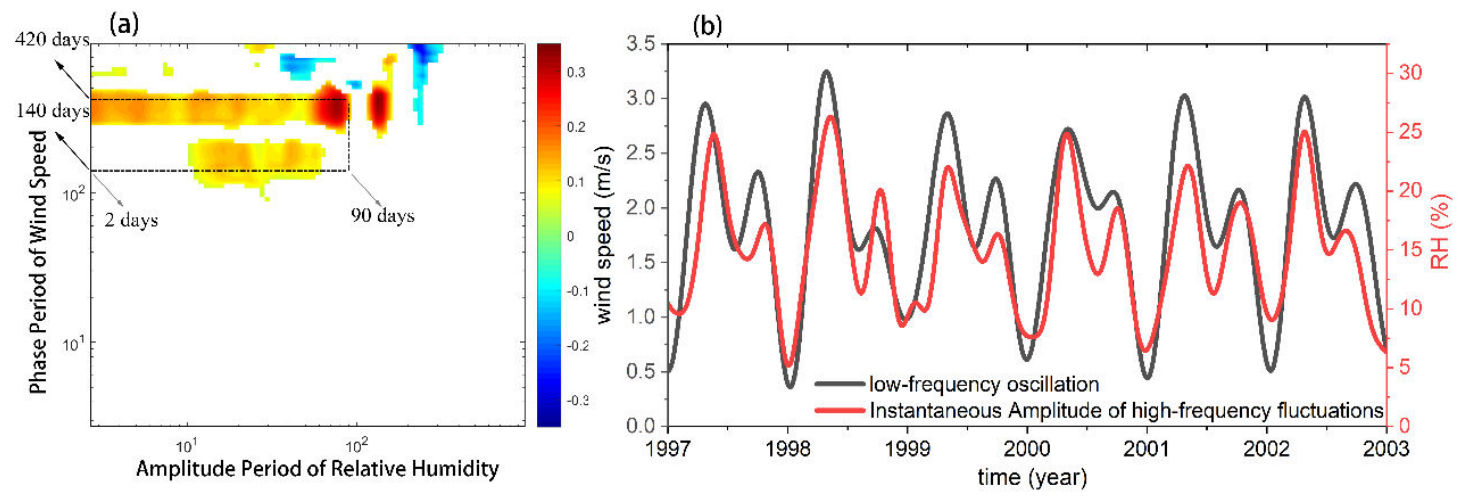

640 Figure 3. (a) The correlation map between wind speed phase and relative humidity (RH) amplitude at station 50136 in Northeast China. The value of the colored area represents the range with the significant Pearson correlation between the instantaneous phases of wind speed and the instantaneous amplitude of RH for the corresponding frequency bands. The significance level for the correlation map, obtained by 1000 phase-random surrogates, is coded in color if they are greater than $95 \%$ of surrogates' results. The significant correlation band of period 140 420 days for wind speed phase and period 2 90 days for RH amplitude indicates the cross-scale modulation of the phase of low-frequency oscillation in the daily wind speed on the amplitude of high-frequency fluctuations in the daily RH. (b) Wind speed low-frequency oscillation with a period of 140 420 days (CCWT as a filter) and RH high-frequency fluctuation amplitude with a period of 2 90 days (the instantaneous amplitude extracted by CCWT and filters out fluctuations less than 90 days). The result is calculated from daily data of station 50136 . 


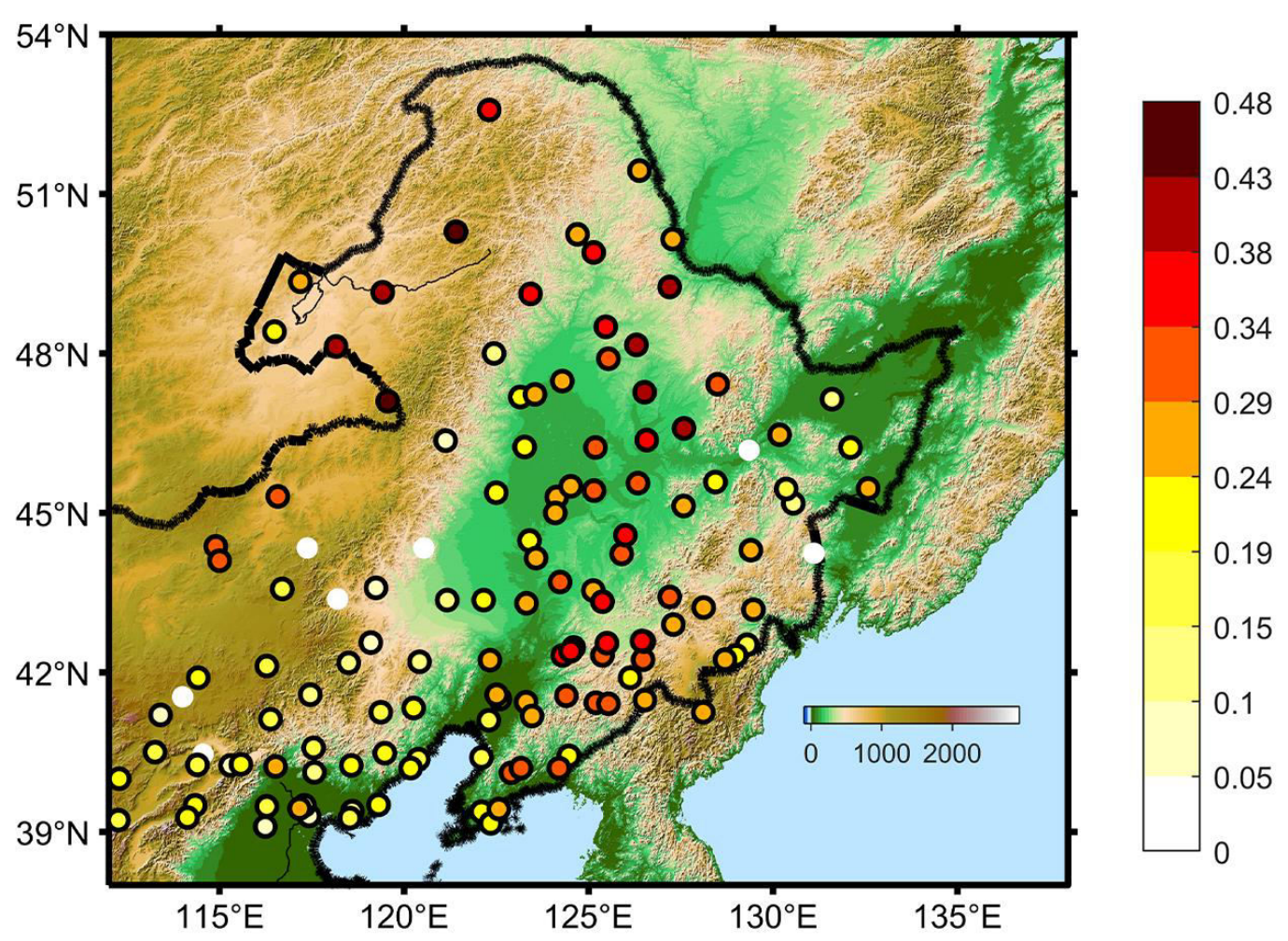

655 Figure 4. The distribution of Amplitude Modulation (AM) index over Northeast China (same as the pink dash rectangle in Figure 5). The points with black circles outside represent the station with significant amplitude modulation between wind speed and RH. The AM index is significant when it is greater than the $95 \%$ results of 1000 phase randomized surrogates after the same procedure. The background color shows the elevation of the area. Most stations with significant AM indexes indicate the strong amplitude modulation effect of wind speed on RH over this area.

661

662

663

664

665

666 


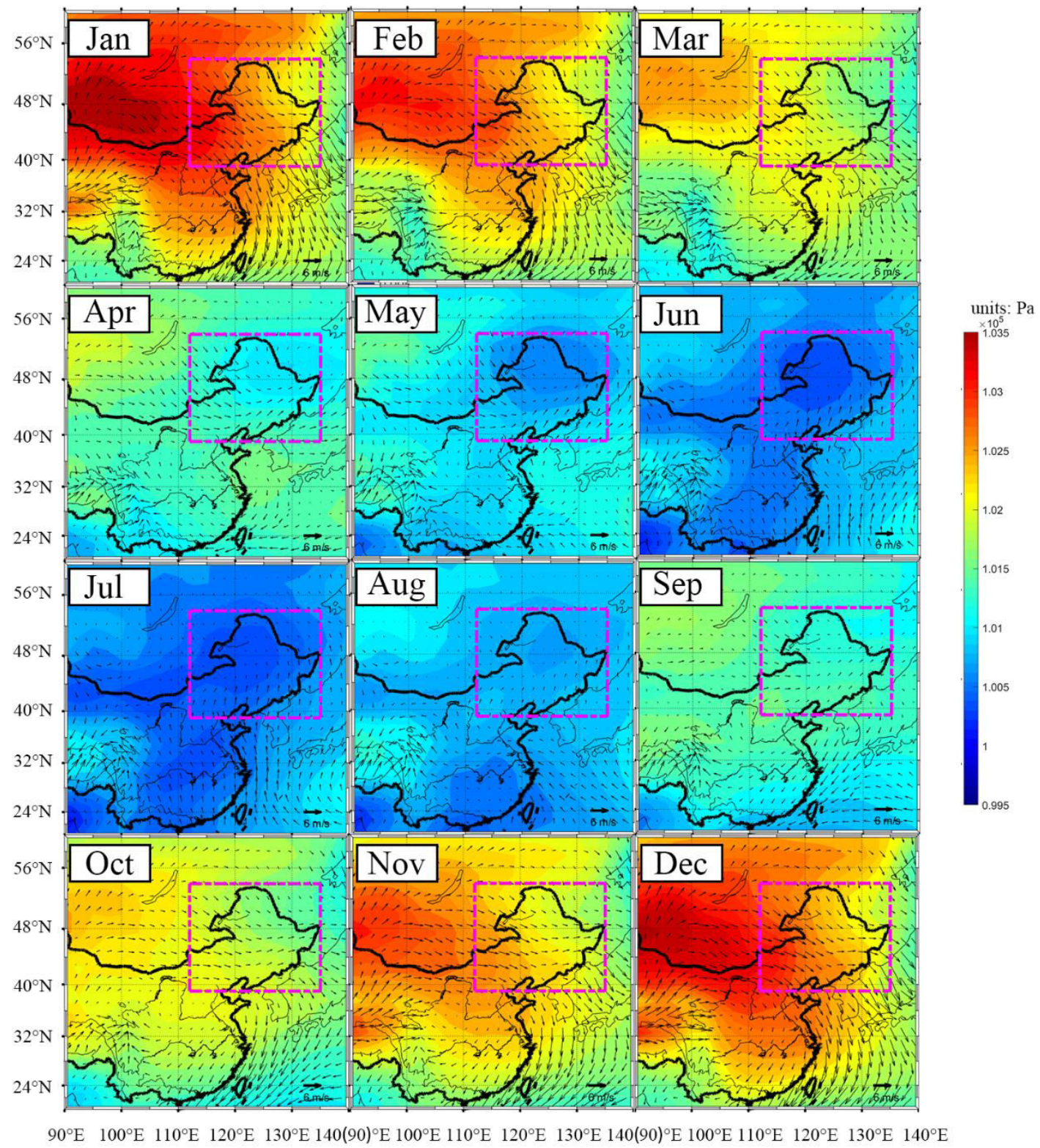

Figure 5. Monthly averages of wind speed $(\mathrm{m} / \mathrm{s})$ and sea level pressure $(\mathrm{Pa})$ in a year. The black vector in the figure represents the wind speed intensity and direction, and the background color shading represents the sea level pressure $(\mathrm{Pa})$. Both data are from the reanalysis dataset. The pink dash rectangle represents Northeast China, which is from $112^{\circ} \mathrm{E}$ to $135^{\circ} \mathrm{E}, 39^{\circ} \mathrm{N}$ to $54^{\circ} \mathrm{N}$. The monthly mean of the wind and sea level pressure exhibits the evolution of monsoons in a year over Northeast China. The monthly mean map in January and February shows the features of the Winter East Asian monsoon with mainly northwestern and western wind. Then the Winter East Asian monsoon decays and transits to Summer East Asian monsoon with the transition time in Apr and May. The map in June, July, and August shows the Summer East Asian monsoon with the mainly south wind. And the map in September and October show the transition from summer monsoon to winter monsoon, finally returning to the winter monsoon in December. 


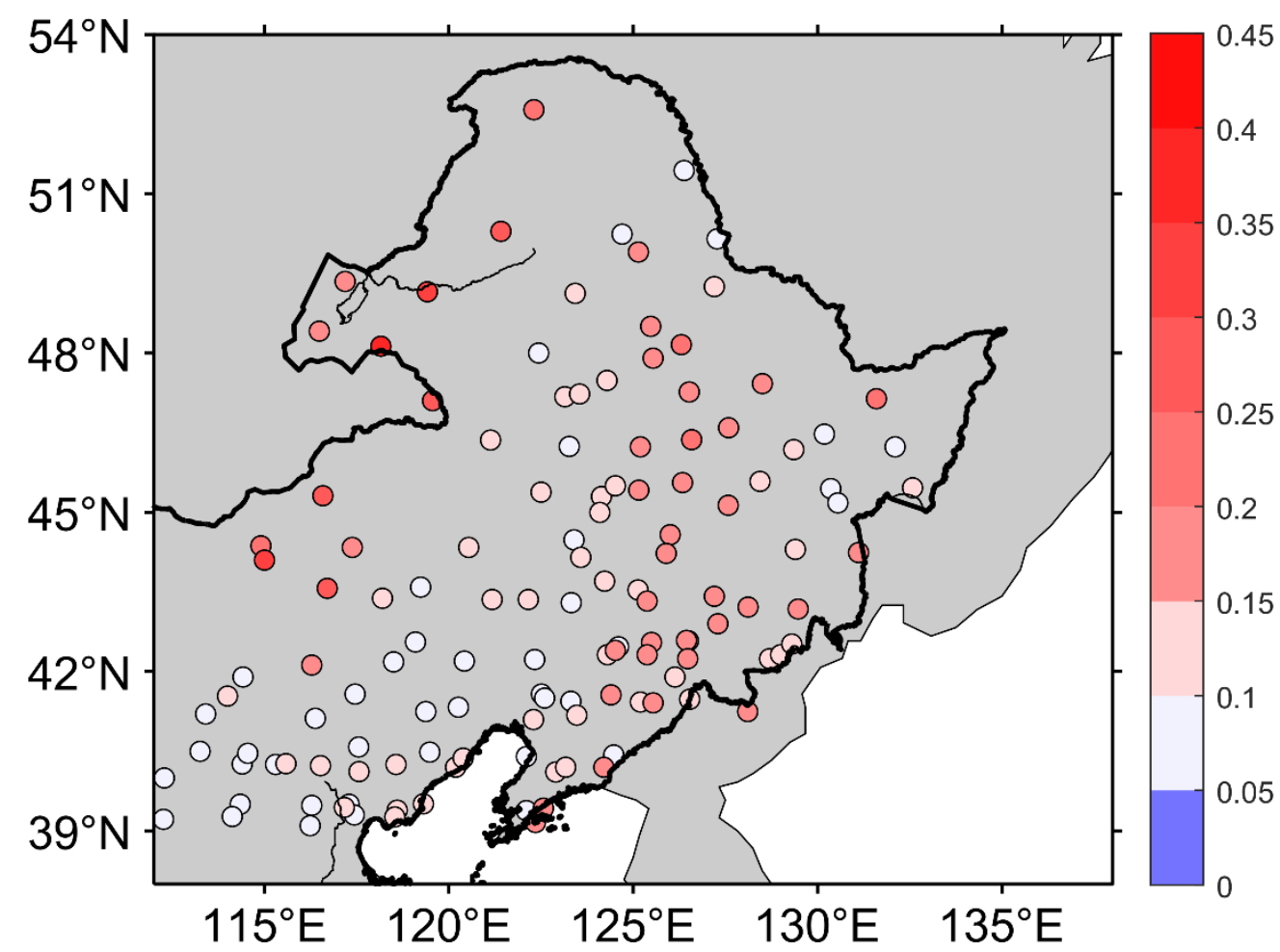

682 Figure 6. The distribution of multi-fractal strength of RH anomalies over Northeast China 683 calculated by the ESS-MF-DFA method. The multi-fractal strength is significant when the value 684 above 0.05 . Most stations of this area show strong multi-fractal features, representing strong 685 nonlinear characteristics. 